\title{
ASMA OCUPACIONAL
}

\author{
OCCUPATIONAL ASTHMA
}

Willy Sarti

Coordenador da Divisão de Imunologia Clínica do Departamento de Clínica Médica da Faculdade de Medicina de Ribeirão Preto da Universidade de São Paulo.

CorRespondêncIA: Willy Sarti - Departamento de Clínica Médica - Hospital das Clínicas da Faculdade de Medicina de Ribeirão Preto - Campus Universitário - CEP: 14048-900 - Ribeirão Preto, SP.

SARTI W. Asma ocupacional. Medicina, Ribeirão Preto, 30: 383-391, jul./set. 1997.

RESUMO: Nesta revisão da asma causada por estímulos próprios do ambiente de trabalho -asma ocupacional - são discutidas sua conceituação, classificação, agentes desencadeantes, fisiopatologia, critérios diagnósticos e diagnóstico diferencial, princípios de tratamento e prognóstico. É também apresentado um caso clínico ilustrativo, relacionado à exposição ambiental em indústria de calçados.

UNITERMOS: Asma. Exposição Ambiental. Doenças Ocupacionais.

\section{INTRODUÇÃO}

A primeira descrição de asma ocupacional foi feita em 1700, em Pádova, na Itália, por Bernardino Ramazzini. Em seu trabalho "De Morbis Artificum", a doença dos artesãos, descreve os sintomas de tosse e dispnéia, que acometem os padeiros, moleiros e trabalhadores em armazéns de cereais. Ramazzini supunha que a causa da obstrução brônquica era devida à formação de uma cola ou pasta, pela deposição de farinha nas vias aéreas. Discutiu a possibilidade de prevenção e confessava que desconhecia qualquer tratamento eficaz para impedir os malefícios e as perigosas conseqüências do pó de farinha na saúde humana ${ }^{1}$.

Entretanto, a asma dos padeiros tem sido referida desde a Antigüidade, pois foi documentado que escravos romanos, padeiros e moleiros, tinham que usar máscara e luvas, quando em contacto com a farinha ${ }^{1}$.

Desde Ramazzini, vários autores estudaram a asma relacionada à profissão de padeiro, sendo, desde então, conhecida como "Asma dos Padeiros".
O caráter alérgico da doença foi reconhecido, pela primeira vez, em 1909, por Cole, que descreveu um caso de alergia ao trigo com "scratch test" positivo. A seguir, em 1916, Schloss demonstrou testes cutâneos de reação imediata ao extrato de farinha de trigo. Em 1929, De Besche transferiu passivamente a reatividade cutânea, com soros de padeiros asmáticos, de acordo com a técnica de PRAUSNITZ-KÜSTNER, dando, assim, suporte à teoria da presença de anticorpos reagínicos na alergia por farinha de trigo ${ }^{1}$.

Atualmente, é reconhecido amplamente que a "asma dos padeiros" é devida à reação de hipersensibilidade imediata, mediada por IgE e provocada pela inalação de antígenos da farinha de trigo ${ }^{2,3}$.

\section{EPIDEMIOLOGIA}

Nos dias atuais, a asma ocupacional tornou-se a doença pulmonar ocupacional mais prevalente nos países desenvolvidos. Programas de vigilância, em vários países, têm revelado que a asma ocorre entre $26 \%$ e $52 \%$ das doenças respiratórias ocupacionais ${ }^{4 / 7}$. 
Nos Estados Unidos, os casos novos de asma ocupacional têm sido estimados em $15 \%$.

A alergia ocupacional representa, hoje, um problema de extensão mundial, com tendência a se agravar em virtude da industrialização e do surgimento de novas substâncias.

Até o presente, têm sido descritos mais de duzentos e cinqüenta agentes que causam asma ocupacional. Os isocianatos são largamente usados na indústria e são responsáveis pela forma mais comum da doença. São usados em fundição de metais, composição de substâncias plásticas e em tintas e vernizes. Cerca de $10 \%$ das pessoas expostas aos isocianatos desenvolvem asma ${ }^{8}$.

\section{CLASSIFICAÇÃO}

Há duas categorias de asma que ocorrem no local de trabalho; asma ocupacional e asma agravada no local de trabalho.

A asma ocupacional é caracterizada pelo quadro obstrutivo e hiperreatividade das vias aéreas, devido a condições próprias do ambiente de trabalho e não por estímulos de fora do local de trabalho. A asma agravada é preexistente e é agravada por fatores irritantes do ambiente de trabalho.

Dois tipos de asma ocupacional podem ser diferenciados por conta de um período de latência, que pode haver ou não.
A asma ocupacional com um período de latência é a mais comum e desenvolve-se após um período de exposição que varia de semanas até vários anos. Aqui estão incluídas as asmas ocupacionais com carácter imunológico, embora nem todos os agentes envolvidos tenham tido os seus mecanismos imunológicos identificados.

A asma ocupacional sem período de latência ocorre após a exposição a altas concentrações de gases, fumo ou substâncias químicas, em alguma ou várias ocasiões ${ }^{8,9}$.

\section{AGENTES CAUSADORES}

Os agentes causadores da asma ocupacional formam uma lista longa e com tendência a aumentar. As substâncias envolvidas na asma com latência encontram-se entre largo espectro de substâncias naturais e sintéticas, encontradas em diversos processos industriais e em variados materiais de uso corrente, em várias atividades profissionais ${ }^{10}$. Estes agentes podem ser subdivididos entre aqueles que são $\operatorname{IgE}$ dependentes e aqueles IgE independentes (Tabela I), diferindo na apresentação clínica, no tipo de reação produzida durante os testes de provocação e, também, nas características das pessoas envolvidas (Tabela II).

Gases irritantes como cloro ou amônia são os agentes mais comumente responsáveis pela indução de asma sem latência ${ }^{8}$.

Tabela I - Classificação e características da asma ocupacional*

\begin{tabular}{|c|c|c|c|}
\hline \multirow{2}{*}{ Características } & \multicolumn{2}{|c|}{ Asma com latência } & \multirow{2}{*}{ Asma sem latência } \\
\hline & $\operatorname{lgE}$ dependente & $\operatorname{lgE}$ independente & \\
\hline \multicolumn{4}{|l|}{ Clínicas } \\
\hline $\begin{array}{l}\text { Tempo de exposição } \\
\text { Tipo de resposta ao teste } \\
\text { de provocação }\end{array}$ & $\begin{array}{l}\text { longo } \\
\text { imediata dupla }\end{array}$ & $\begin{array}{l}\text { curto } \\
\text { tardia }\end{array}$ & $\begin{array}{l}\text { em horas } \\
\text { desconhecida }\end{array}$ \\
\hline \multicolumn{4}{|l|}{ Epidemiológicas } \\
\hline $\begin{array}{l}\text { Prevalência na população exposta } \\
\text { Fatores predisponentes }\end{array}$ & $\begin{array}{l}<5 \% \\
\text { Atopia } \\
\text { fumo? }\end{array}$ & $\begin{array}{l}>5 \% \\
\text { desconhecidos }\end{array}$ & $\begin{array}{l}\text { desconhecida } \\
\text { desconhecidos }\end{array}$ \\
\hline \multicolumn{4}{|l|}{ Patológicas } \\
\hline $\begin{array}{l}\text { Ativação de Linfócitos } \\
\text { Ativação de Eosinófilos } \\
\text { Fibrose Subepitelial } \\
\text { Espessamento da membrana basal } \\
\text { Descamação Epitelial }\end{array}$ & $\begin{array}{l}++++ \\
++++ \\
+ \\
++++ \\
+\end{array}$ & $\begin{array}{l}++++ \\
+ \\
++++ \\
+\end{array}$ & $\begin{array}{l}+ \\
+++ \\
++++ \\
++++ \\
++++\end{array}$ \\
\hline
\end{tabular}


Tabela II - Agentes que mais freqüentemente causam asma ocupacional ${ }^{\star}$

\begin{tabular}{|c|c|}
\hline Agentes & Tipo de ocupação \\
\hline $\begin{array}{l}\text { Origem animal } \\
\text { Epitélios de cães, gatos, ratos, } \\
\text { cobaias, etc. } \\
\text { Insetos e ácaros de cereais } \\
\text { Frutos do mar }\end{array}$ & $\begin{array}{l}\text { - veterinários } \\
\text { - laboratoristas } \\
\text { - trabalhadores em armazéns } \\
\text { - trabalhadores na indústria de processamento }\end{array}$ \\
\hline $\begin{array}{l}\text { Origem vegetal ou bacteriana } \\
\text { Cereais e farinha } \\
\text { Pó de serra } \\
\text { Enzimas }\end{array}$ & $\begin{array}{l}\text { - padeiros e moleiros } \\
\text { - marceneiros } \\
\text { - trabalhadores na indústria farmacêutica } \\
\text { - trabalhadores na indústria de detergentes } \\
\text { - padeiros }\end{array}$ \\
\hline $\begin{array}{l}\text { Breu } \\
\text { Gomas } \\
\text { Látex }\end{array}$ & $\begin{array}{l}\text { - soldadores } \\
\text { - trabalhadores na indústria farmacêutica } \\
\text { - trabalhadores na indústria de tapetes } \\
\text { - profissionais da saúde }\end{array}$ \\
\hline $\begin{array}{l}\text { Origem Química } \\
\text { Isocianatos }\end{array}$ & $\begin{array}{l}\text { - pintores } \\
\text { - trabalhadores nas indústrias de plástico, borracha, espumas } \\
\text { - laqueadores, soldadores }\end{array}$ \\
\hline $\begin{array}{l}\text { Aminas } \\
\text { Epóxi e Acrilatos } \\
\text { Corantes } \\
\text { Fumos } \\
\text { Persulfatos } \\
\text { Cromo-Níquel* } \\
\text { Formaldeído }\end{array}$ & $\begin{array}{l}\text { - manuseadores de adesivos, pintores } \\
\text { - trabalhadores na indústria textil } \\
\text { - trabalhadores na indústria eletrônica } \\
\text { - cabeleireiros } \\
\text { - trabalhadores na indústria de cromeação, niquelação } \\
\text { - trabalhadores em hospitais }\end{array}$ \\
\hline
\end{tabular}

* Adaptado de: Grammer CG. (ref. 23).

\section{FISIOPATOLOGIA}

A asma ocupacional com latência apresenta hiperreatividade brônquica, induzida pela metacolina ou histamina. Esta reatividade decresce com o tempo de afastamento da exposição e tende a retornar, gradativamente, após exposição ao agente sensibilizante.
Quando estudada por meio dos testes de provocação, pode apresentar-se de maneira variada. As reações podem ser imediatas isoladas, tardias isoladas, bifásicas (imediata e tardia em sequiência) ou contínuas ${ }^{11}$ (Figura 1). A reação imediata isolada ocorre em poucos minutos após a provocação, atingindo o máximo em torno de trinta minutos e tende a desaparecer
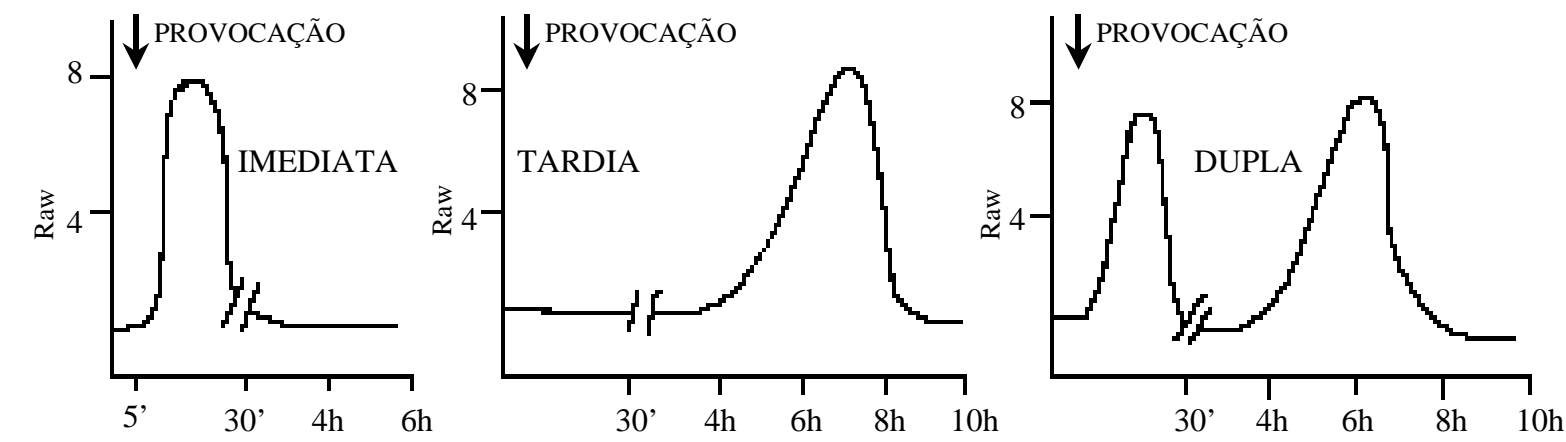

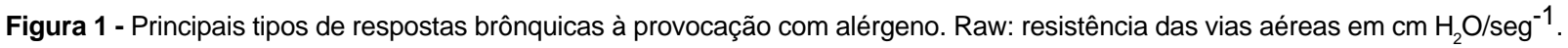


em sessenta a noventa minutos. Comporta-se, assim, da mesma forma que a asma alérgica clássica, frente a teste de provocação com agente sensibilizante.

Esta semelhança com a asma clássica e o imediatismo da resposta sugerem mecanismo de hipersensibilidade do tipo imediato, envolvendo, portanto, a participação de IgE e mastócitos sensibilizados. Uma reação tardia isolada ocorre de quatro a seis horas após a provocação com o agente específico e atinge o máximo em oito a doze horas, evanescendo após vinte e quatro a trinta e seis horas. Ao que tudo indica, é mediada também por IgE, e possivelmente por IgG, talvez a IgG4. A reação bifásica é constituída por uma reação imediata que desaparece espontaneamente, seguida de reação tardia, duas a seis horas mais tarde. A reação contínua não apresenta remissão entre as respostas imediatas e tardias. Há ainda a reação repetitiva que persiste por dias, após a provocação ${ }^{1,8,11}$. Estes padrões diferentes de respostas à provocação não são bem compreendidos, porém podem estar relacionados a variados mecanismos de resposta inflamatória na asma brônquica, frente a diferentes características dos agentes provocadores, bem como, ainda, dependentes dos tipos de protocolos de provocação que são usados.

A maioria dos compostos de peso molecular elevado, isto é, acima de 5.000 daltons, são indutores da produção de IgE específica, enquanto que algumas substâncias de baixo peso molecular, como os anidridos e os sais de platina, podem atuar como haptenos, ligando-se a proteínas plasmáticas ou teciduais induzindo à produção de IgE específica ${ }^{11,12,13}$.

Entretanto, para a maioria dos compostos de baixo peso molecular, tais como os isocianatos, a produção de IgE específica tem sido demonstrada em apenas uns poucos casos e, ainda assim, a presença de igE específica tem sido considerada como um marcador da exposição ao antígeno, e não necessariamente como responsável pela reação ${ }^{14}$.

O papel dos linfócitos, na asma ocupacional, bem como na asma clássica, está sob intensa investigação. Alguns estudos sugerem um papel direto, importante no processo inflamatório da mucosa brônquica, mais do que a eventual modulação da resposta IgE. As alterações anatomopatológicas encontradas na asma ocupacional são semelhantes àquelas das outras formas de asma. A acumulação de células inflamatórias e, entre elas, principalmente os eosinófilos, juntamente com o edema, hipertrofia da musculatura lisa e fibrose subepitelial são responsáveis pelo espessamento das paredes brônquicas, que, com a secreção de muco, leva à obstrução ${ }^{15 / 17}$. Estas alterações são encontradas em pulmões de pacientes que morreram por "asma" induzida por isocianato ${ }^{18}$ e em biópsias de mucosa brônquica de pacientes portadores de asma ocupacional $^{8,19}$.

A asma ocupacional sem latência é induzida por agentes irritativos e é mediada por mecanismo desconhecido, embora as alterações patológicas nela encontradas sejam iguais àquelas dos pacientes com asma ocupacional com latência ${ }^{20}$. Entretanto, estudos mais recentes sugerem algumas diferenças, com achados de fibrose mais marcantes na parede brônquica e menor número de linfócitos $\mathrm{T}$, sugerindo ausência de mecanismo imunológico na asma sem latência ${ }^{21,22}$.

\section{DIAGNÓSTICO}

Ao se examinar um trabalhador suspeito de ter asma ocupacional, é necessário, primeiramente, estabelecer o diagnóstico de asma e depois buscar o diagnóstico de asma causada por exposição ocupacional.

Os critérios necessários para se estabelecer a relação com a ocupação dependem do propósito com que o diagnóstico é feito. Assim, os requisitos são mais marcantes, se o propósito é o diagnóstico médico, e a relação com o trabalho deve ser demonstrada de modo bem objetivo. Se o propósito tiver objetivos epidemiológicos, os critérios necessários podem ser menos marcantes, o que por sua vez aumenta a sensibilidade da identificação de casos.

O diagnóstico diferencial deve ser feito com as condições listadas na Tabela III, que comumente se confundem com o quadro clínico de asma ocupacional.

\section{Tabela III - Diagnóstico diferencial da asma ocu-} pacional

1. Asma preexistente ou doença obstrutiva crônica (DPOC), exacerbadas pelo frio, exercícios ou substâncias irritantes no ambiente de trabalho.

2. Desenvolvimento de asma ou DPOC no local de trabalho, porém não relacionada com exposição a agentes sensibilizantes.

3. Pneumonite por hipersensibilidade.

4. Outras doenças respiratórias, não asmáticas, como bissinose, pneumoconiose, etc.

5. Distúrbio do pânico ou outras manifestações psicossomáticas, que causam dispnéia.

6. Simulação. 
A falta de agente sensibilizante específico afasta o diagnóstico de asma ocupacional, quando se tratar de asma preexistente ou DPOC ou asma que se desenvolve no local de trabalho, sem relação com uma exposição sensibilizante específica. No caso de bissinose ou pneumoconiose, a história, exame físico, radiologia e testes de função pulmonar são diferentes daqueles próprios da asma. A dificuldade maior no diagnóstico diferencial situa-se nas manifestações de causa psicossomática e nos casos de simulação. Nestes casos, a história deve ser deixada de lado e o diagnóstico deve se basear no exame físico e em testes objetivos de função pulmonar e testes imunológicos. Uma vez afastadas outras doenças respiratórias, a atenção deve ser focalizada na tentativa de demonstrar a associação entre a asma e a ocupação.

Em primeiro lugar, deve-se obter uma história detalhada sobre as exposições, passadas e presentes às substâncias ambientais relacionadas ao trabalho; se possível, um relato cronológico dos sintomas e se há melhora de sintomatologia, quando o paciente está ausente do local de trabalho, por tempo prolongado. Nos casos mais evidentes, pode-se obter uma história em que as queixas de dispnéia e sibilância apresentam-se no final da jornada de trabalho, para, no dia seguinte pela manhã, apresentar-se relativamente assintomático, mostrando, também, nítida melhora nos fins de semana. Nas ausências mais prolongadas do trabalho, como nas férias ou licença para tratamento, a recuperação é total. Entretanto, a maioria dos casos não se apresenta tipicamente desta maneira e, assim, recursos objetivos são necessários para diagnóstico. Têm sido descritos vários algoritmos para a investigação clínica, que são muito semelhantes entre $\mathrm{si}^{8,23}$ (Figura 2).

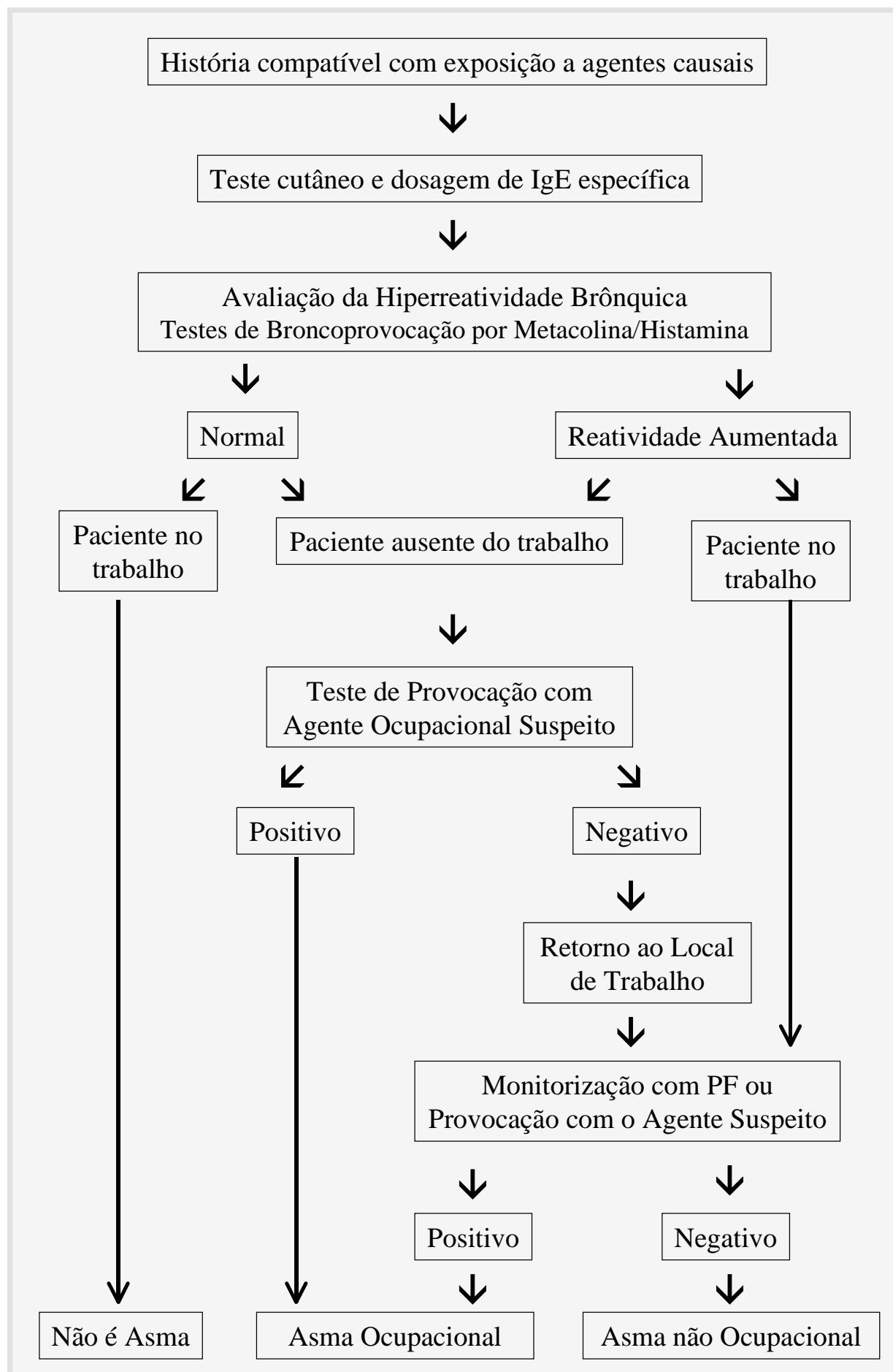

Figura 2 - Algoritmo para investigação da asma ocupacional. 
Para aqueles casos IgE dependentes, o teste cutâneo e a dosagem de IgE específica podem ser realizados, se o alérgeno apropriado for disponível.

A medida da hiperreatividade brônquica com metocolina/histamina é um passo importante para afastar a asma ocupacional, bem como qualquer outro tipo de asma. Pacientes, submetidos ao ambiente ocupacional, que não apresentem hiperreatividade, podem ser excluídos sumariamente do diagnóstico de asma ocupacional. Entretanto, a positividade a este teste, indica necessidade de exposição ao suposto antígeno ocupacional, para confirmação do diagnóstico.

Uma abordagem possível é a exposição do paciente ao ambiente ocupacional, monitorizado por medidas de pico do fluxo expiratório. Entretanto, este método depende da cooperação do paciente e do registro correto das observações. Para maior efetividade e credibilidade deste método, seria necessário que as medidas efetuadas no ambiente ocupacional fossem acompanhadas por um técnico. Entretanto, quando possível, a melhor condição para diagnóstico é o teste de provocação, para reproduzir a sintomatologia do paciente, em ambiente laboratorial controlado. Os pacientes devem ser expostos lentamente a doses sucessivamente crescentes do agente suspeito, para evitar reações graves ${ }^{11,24}$. O teste de provocação, específico, pode produzir falsos resultados negativos, se for usado o agente suspeito errado ou se o paciente estiver afastado por longo tempo do local de trabalho. A história de associação temporal entre os sintomas asmáticos e a exposição ocupacional não se constitui em condição segura para o estabelecimento do diagnóstico de asma ocupacional, porque a asma é uma doença freqüente, e a exposição concomitante a agentes potencialmente causadores de asma ocupacional pode se dar casualmente.

Para investigações epidemiológicas, de trabalhadores sob risco de asma ocupacional, existe um questionário que inclui informações sobre sintomas relacionados com o trabalho ${ }^{25,26}$.

\section{CASO CLÍNICO}

Identificação: E.A.S. 40 anos, sexo masculino, brasileiro, pardo, sapateiro, procedente de Franca - SP.

HMA - Relata o paciente que, há cerca de oito meses, começou a sentir coceira na garganta acompanhada de espirros e corrimento nasal hialino, e que surgem até o presente, 2 a 4 horas após iniciar o tra- balho. Após seis a oito horas do início do trabalho, apresenta tosse seca, chiadeira no peito e falta de ar. Faz uso de Franol e melhora do quadro respiratório. O paciente trabalha em fábrica de calçados, onde opera uma máquina com escovas para polir saltos e solas de sapatos, após haverem sido tingidos. O micro ambiente do local de trabalho fica tomado por uma nuvem densa de pó de tinta para calçados. Não usa máscara ou qualquer equipamento de proteção. Quando se afasta do trabalho, para tratamento a sintomatologia desaparece. Quando volta ao trabalho, os sintomas reaparecem em três a quatro dias. Nega passado de manifestações alérgicas, como eczema, urticária, rinite e asma brônquica.

Atualmente, está sendo tratado de úlcera péptica e refere constipação intestinal de até dois dias. Nega palpitações, cianose e edemas.

Antecedentes pessoais sem interesse. Nega, enfermidade semelhante à sua entre os seus familiares próximos.

Exame Físico: bom estado geral, afebril, hidratado e ativo. Mucosas úmidas e coradas. Tecido subcutâneo sem edemas e distribuição normal da gordura. Gânglios não palpáveis. Musculatura e esqueleto sem alterações. O exame físico do tórax não revelou anormalidades. Coração, duas bulhas rítmicas, norfonéticas, sem sopros. Pressão arterial igual a 120x80 mmHg, Frequiência de pulso igual à frequiência cardíaca, igual a setenta e seis batimentos por minuto. Abdome plano, normotenso, sem massas tumorais palpáveis. Fígado e baço não palpáveis.

\section{Exames Complementares:}

Teste cutâneo (Prick Test) negativo para uma bateria composta de vinte e quatro antígenos ambientais comuns.

Teste de Função Pulmonar dentro da normalidade, sem sinais de distúrbios ventilatórios, restritivos ou obstrutivos. lidade.

Raio X de tórax, não revelou qualquer anorma-

Exame direto e cultura de escarro, negativos para BAAR.

Teste de Tuberculina $=$ reator forte.

Exame Parasitológico de Fezes $=$ negativo $\mathrm{GV}=5.000 .000 / \mathrm{mm}^{3} \# \mathrm{~GB}=7.200 / \mathrm{mm}^{3}$ \# $\mathrm{Hb}=16,2 \mathrm{~g} / \mathrm{dL}$

Neutrófilos Bast. $=08 \% ; \quad$ Neutrófilos Seg. $=66 \%$; Eosinófilos $=04 \%$; Basófilos $=00 \%$; Linfócitos $=20 \%$; Monócitos $=02 \%$; Plasmócitos $=00 \%$; Urina rotina: Sem alterações. 
Teste de Broncoprovocação: utilizado o pó derivado da atividade da máquina de polir calçados, como substância teste, e carvão vegetal em pó, como placebo. Em ambos os casos, o procedimento foi como segue: $\mathrm{O}$ paciente foi confinado em uma cabine de madeira, envidraçada de $1 \mathrm{~m}^{2}$ de área por dois metros de altura. No interior, sobre uma pequena mesa, duas bandejas, uma vazia e outra contendo o pó. Durante trinta minutos, o paciente passava o conteúdo de uma bandeja para a outra, de modo a provocar a suspensão de poeira naquele ambiente. A cada quinze minutos, durante uma hora, foram feitas medidas do FEV1. A seguir, as medidas foram feitas a cada hora durante dez horas. Como pode ser verificado pela Figura 3, o paciente apresentou medidas de VEF1 normais, durante a provocação com o placebo. Mostrou resposta dupla de queda dos valores do VEF1, quando da broncoprovocação com o pó de tinta para calçado.

Neste caso, a história clínica típica, associada a uma resposta obstrutiva à provocação com a substância suspeita, sugere o diagnóstico de asma ocupacional, provocada pela inalação, intensa e por longo tempo, da suspensão do pó de tinta.

Uma injeção intradérmica, de $0,02 \mathrm{ML}$ de uma diluição a 1/100.000 da tinta original, provocou uma resposta inflamatória quatro horas depois. Biópsia da área inflamada revelou infiltrado de neutrófilos e linfócitos, bem como, por imunofluorescência, pôde-se apreciar a deposição de complemento no endotélio capilar.

É possível que componentes da tinta, como hidrocarbonetos, e principalmente cera sejam ativadores do sistema do complemento e, assim, responsáveis pela lesão inflamatória cutânea. Entretanto, inferir o mesmo mecanismo para a inflamação da mucosa brônquica seria alçar um patamar de especulação ainda maior.

Maiores investigações seriam necessárias para tentar identificar qual ou quais os componentes deste pó seriam responsáveis pela reação inflamatória, bem como averiguar se este por pó de tinta para calçados. caso de asma ocupacional está entre aqueles IgE dependentes ou $\operatorname{IgE}$ independentes.

A conduta terapêutica foi o afastamento do paciente, daquele microambiente, o que foi suficiente para o desaparecimento imediato da sintomatologia. Foi transferido para outro setor da fábrica, após o patrão ter tomado conhecimento da situação.

\section{TRATAMENTO}

O melhor tratamento para asma ocupacional consiste no afastamento do paciente do agente provocador. O trabalhador pode ser mudado de lugar, dentro da mesma empresa, ou ser transferido para outro tipo de ocupação. O uso de máscaras ou outro método para reduzir a exposição não é efetivo para os pacientes com asma ocupacional com período de latência, pois, estes indivíduos tendem a reagir frente a diminutas quantidades do agente. Quando a asma for do tipo irritativo, é possível alguma acomodação, pela melhoria das condições ambientais. Aqui, o papel do médico é importante na conscientização do paciente e do empregador, e na sugestão de vias para solução do problema.

Em qualquer circunstância em que o paciente volte ao mesmo ambiente de trabalho, deve ser acompanhado por observação médica, e, em caso de reaparecimento dos sintomas, deve ser removido da exposição, imediatamente.

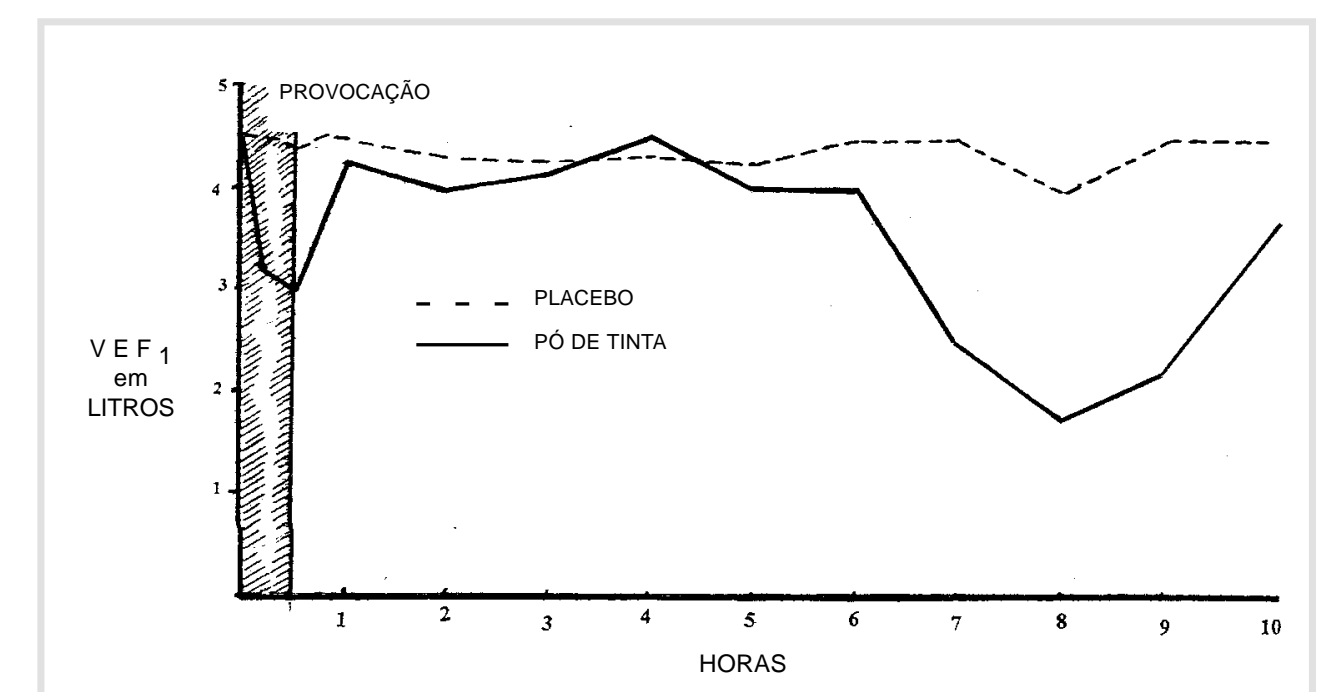

Figura 3 - Teste de broncoprovocação do paciente E.A.S. com asma ocupacional, induzida 
O tratamento medicamentoso na asma ocupacional é o mesmo que para outras formas de asma, mas deve ser apenas complementar ao afastamento do agente. Embora o afastamento do agente causador resulte em melhora, alguns pacientes continuam necessitando medicação por muito tempo, isto é, meses ou anos.

\section{AVALIAÇÃO DO GRAU DE COMPROMETI- MENTO}

O paciente deve ser avaliado, quanto à presença de invalidez temporária ou permanente, quando a sua asma estiver sob bom controle. A avaliação quanto à possibilidade de invalidez permanente deve ser levada a efeito, após dois anos, quando o estado da sintomatologia tenha atingido um platô ${ }^{27,28}$. Um guia para avaliação do grau de comprometimento ou invalidez, provocado pela asma, foi publicado pela American Thoracic Society, onde, além das medidas da função pulmonar, é recomendado que a avaliação inclua o grau de reatividade brônquica, induzida farmacologicamente, ou o grau de reversão da obstrução, induzida pelos betaadrenérgicos, bem como a quantidade mínima de medicação necessária para controle da asma e seu efeito na qualidade de vida do indivíduo ${ }^{29}$.

\section{PROGNÓSTICO}

Uma proporção significante de trabalhadores com asma ocupacional não alcançam a cura completa, após o afastamento do ambiente de trabalho ${ }^{26}$. Os fatores que afetam o prognóstico não são bem conhecidos, entretanto, o prognóstico favorável parece estar associado ao tempo curto de duração dos sintomas (menor que 1 ano), testes de função pulmonar normais e grau baixo de hiperreatividade brônquica ${ }^{30,31}$. Assim, sugere-se que o diagnóstico precoce e a remoção da exposição são fatores importantes para se conseguir a recuperação completa do paciente.

Deve ser enfatizado que a deterioração é a regra para aqueles indivíduos que permanecem expostos após o diagnóstico ${ }^{26,32}$.

\section{PREVENÇÃO}

O objetivo principal na asma ocupacional é a prevenção. Higiene ambiental, tal como melhor ventilação, ou processos de isolamento podem contribuir para melhoria ambiental. O uso de equipamentos de proteção individual é importante e tem seu emprego em alguns casos. A educação do trabalhador acerca da exposição no ambiente de trabalho, seus efeitos na saúde e como minimizá-los tem importância também²3.

SARTI W. Occupational asthma. Medicina, Ribeirão Preto, 30: 383-391, july/sept. 1997.

ABSTRACT: In this review of the asthma caused by stimuli derived from the work environment - occupational asthma - we discuss its concept, classification, triggering agents, pathophysiology, diagnostic criteria and differential diagnosis, therapeutical principles and prognosis. It is also presented a clinical case related to environmental exposition in the shoe industry.

UNITERMS: Asthma. Environmental Exposure. Occupational Diseases.

\section{REFERÊNCIAS BIBLIOGRÁFICAS}

1 - THIEL H. Bakers asthma: A classical occupational allergy, In: SETTIPANE GA, ed. Current treatment of ambulatory asthma. New England and Regional Allergy Proceedings Providence, Rhode Island, p. 169-187, 1986.

2 - WILBUR RD \& WARD GW. Immunologic studies in case of backers' asthma. J Allergy Clin Immunol 58: 366-372, 1976.

3 - NAPOLITANO J \& WEISS NS. Occupational asthma of backers. Ann Allergy 40: 258-261, 1978.
4 - LAGIER F; CARTIER A \& MALO JL. Statistiques medicolegales sur l'asthme profissionnel au Quebec de 1986 a 1988. Rev Mal Respir 7: 337-341, 1990.

5 - MEREDITH SK; TAYLOR VM \& MCDONALD JC. Occupational respiratory disease in United Kingdom 1989; a report to the British Thoracic Society and Society of Occupational Medicine by the SWORD project group. Br J Ind Med 48: 292-298, 1991.

6 - REILLY MJ; ROSENMAN KD \& WATT FC. Surveillance for occupational asthma - Michigan and New Jersey, 1988-1992. MMWR CDC Surveill Summ 43: 9-17, 1994. 
7 - CONTRERAS GR; ROUSSEAU R \& CHAN-YEUNG M. Occupational respiratory diseases in British Columbia, Canadá in 1991. Occup Environ Med 51: 710-712, 1994.

8 - CHANG-YEUNG M \& MALO JL. Current concepts: Occupational asthma. N Eng J Med 333: 107-112, 1995.

9 - CHANG YEUNG M \& MALO JL. Epidemiology of occupational asthma. In: BUSSE WW \& HOLGATE ST, ed. Asthma and rinitis. Blackwell Scientific Publications, Boston, p. 44-57, 1995

10 - CHANG-YEUNG M \& MALO JL. Aetiologic agents in occupational asthma. Eur Respir J 7: 346-371, 1994.

11 - PEPYS J \& HUTCHCROFT BJ. Bronchial provocation tests in etiologic diagnosis and analysis of asthma. Am Rev Respir Dis 112: 829-859, 1975.

12 - ZEISS CR et al. Trimellitic anhydride-induced airway syndromes: clinical and immunologic studies. J Allergy Clin Immunol 60: 96-103, 1977.

13 - PEPYS J; PICKERING CAC \& HUGHES EG. Asthma due to inhaled chemical agents - complex salts of platinum. Clin Allergy 2: 391-396, 1972.

14 - MAPP CE et al. Occupational asthma due to isocyanates. Eur Respir J 1: 273-279, 1988.

15 - KAY AB; CORRIGAN CJ \& FEW AJ. The role of cellular immunology in asthma. Eur Respir J 105s-112s, 1991. Suppl 13.

16 - GALLAGHER JS et al. Diverse profiles of immunoreactivity in toluene diisocyanate (TDI) asthma. J Occup Med 23: 610-616, 1981.

17 - REDLICH CA et al. Immunologic responses to isocyanates in sensitized asthmatic subjects. CHEST 109: 6s-8s, 1996. Suppl.

18 - FABRI LM et al. Fatal asthma in a subject sensitised to toluene diisocyanate. Am Rev Respir Dis 137: 1494-1498, 1988.

19 - SAETTA M et al. Airway mucosal inflamation in occupational asthma induced by toluene diisocyanate. Am Rev Respir Dis 145: 160-168, 1992.

20 - BROOKS SM; WEISS MA \& BERNSTEIN JL. Reactive airways dysfunction syndrome (RADS): persistent asthma syndrome after high level irritant exposures. Chest 88: 376-384, 1985.

21 - GAUTRIN D et al. Is reactive airways dysfunction syndrome a variant of occupational asthma? J Allergy Clin Immunol 93: 12-22, 1994.
22 - CHAN-YEUNG $\mathrm{M}$ et al. Persistent asthma after repeated exposure to high concentrations of gazes in pulpmills. Am J Respir Crit Care Med 149: 1676-1680, 1994.

23 - GRAMMER CG. Occupational asthma. Immunol Allergy Clin North Am 13: 769-783, 1993.

24 - STERK PJ et al. Airway responsiviness: standardized challenge testing with pharmacological, physical and sensitizing stimuli in adults: Report Working Party Standardization of Lung Function Tests, European Community for Steel and Coal. Eur Respir J 16: 53-83, 1993. Suppl.

25 - BURNEY PGJ et al. Validity and repeatibility of the JUATLD (1984) Bronchial Symptoms Questionaire: an international comparison. Eur Respir J 2: 940-945, 1989.

26 - CHAN-YEUNG M. A clinician's approach to determine the diagnosis, prognosis and therapy of occupational asthma. Med Clin North Am 74: 811-818, 1990.

27 - NATIONAL ASTHMA EDUCATION PROGRAM. Guidelines for the diagnosis and management of asthma. Bethesda, Md., Public Health Service, 1991. (DHHS publication no NIH 91-3042)

28 - CHAN-YEUNG M. Occupational asthma. Chest 98: 148s-161s 1990. Suppl.

29 - AMERICAN THORACIC SOCIETY. Medical Section of the American Lung Association. Guidelines for the evaluation of impairment / disability in patients with asthma. Am Rev Respir Dis 147: 1056-1061, 1993.

30 - HUDSON P et al. Follow up of occupational asthma caused by crab and various agents. J Allergy Clin Immunol 76: 262-271, 1985.

31 - LAM S; WANG R \& CHAN YEUNG M. Non specific bronchial reactivity in occupational asthma. J Allergy Clin Immunol 63: 28-34, 1979

32 - PAGGIARO PL et al. Follow up study of patients with respiratory disease due to toluene diisocyanate (TDI). Clin Allergy 14: 463-468, 1984.

Recebido para publicação em 02/07/97

Aprovado para publicação em 30/07/97 